Documento No. 60

Características de Un Régimen de Promoción de Exportaciones

por

Raúl Miguel Ramos T.

$\mathrm{y}$

Jaime Zabludowsky K.

Enero 1985.

Las ideas contenidas en el presente ensayo son responsabilidad exclusiva de los autores y no reflejan la posición del Banco de México 


\section{CARACTERÍSTICAS DE UN RÉGIMEN DE PROMOCIÓN DE EXPORTACIONES}

La promoción de las exportaciones no petroleras ocupa un lugar preponderante entre los objetivos de la política económica de la presente administración. Se ha reconocido que una condición necesaria para lograr un mayor dinamismo de las ventas en el exterior es garantizar que el sector exportador cuente con insumos y materias primas a precios y calidades internacionales. Con ese fin, se instrumentó recientemente un régimen de importación temporal para los exportadores. Sin embargo, dicho régimen presenta algunos inconvenientes que le restan efectividad. En esta nota se describen las principales características del esquema vigente, se señalan sus deficiencias y se propone un régimen alternativo, que podría coexistir con el actual.

\section{Régimen actual}

Actualmente se permite la importación libre de aranceles de los insumos utilizados en la producción para la exportación. Es decir, los aranceles no pagados por los exportadores están determinados por la siguiente fórmula:

$\begin{array}{lll}(\text { Arancel })= & \begin{array}{c}\text { (Tasa de) } \\ \text { No pagado }\end{array} & \begin{array}{l}\text { (Valor de) } \mathrm{x} \\ \text { exportaciones }\end{array}\end{array}$

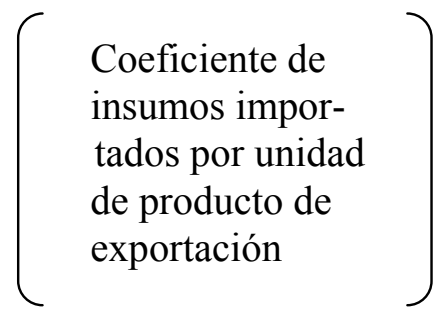

La aplicación de este esquema requiere de la identificación física de los insumos importados en los productos que posteriormente se exportan. De acuerdo a la experiencia de algunos exportadores, esto limita en la práctica la efectividad del esquema:

a) La identificación de los insumos importados en productos de exportación es usualmente difícil y en muchos casos, virtualmente imposible. Esto trae consigo trámites de aduanas más complicados, que entorpecen el proceso de exportación. 
b) El proceso de exportación requiere de celeridad en la cotización de los precios del producto a exportar y en la entrega física del mismo. Por ello, en casos en los cuales la importación de los insumos intermedios toma un tiempo considerable, el esquema actual de importación temporal no facilita las exportaciones.

c) Aunque parezcan muy similares a los insumos nacionales, en algunos casos los insumos importados no son sustitutos perfectos de éstos desde un punto de vista técnico. Bajo estas circunstancias, ajustar los procesos de producción para utilizar insumos extranjeros únicamente en la producción para exportación, puede resultar excesivamente costoso.

d) Crea la necesidad de establecer y vigilar el cumplimiento de criterios que determinen los márgenes permisibles de mermas y desperdicios, con los costos y complicaciones administrativas que esto implica. Además, la disposición de las mermas y desperdicios está sujeta a un procedimiento complicado.

\section{Esquema propuesto}

Este esquema funcionaría de la siguiente manera. Se concedería a los exportadores permiso automático para importar los insumos que deseen hasta por un valor igual al de los Compromisos de Ventas de Divisas que hayan liquidado. La única restricción sobre la naturaleza de los insumos que podrían ser importados bajo este régimen, sería la de no estar comprendidos en una lista de prohibiciones que incluiría los bienes de consumo no susceptibles de ser transformados, especialmente los suntuarios. Al momento de efectuar la importación, la empresa tendría que pagar íntegramente los aranceles correspondientes, pero éstos se le devolverían parcial o totalmente cuando se llevara a cabo la exportación. El monto de aranceles devueltos se determinaría de acuerdo a la siguiente regla:

$$
\begin{array}{llr}
\begin{array}{l}
\text { Arancel })= \\
\text { devuelto }
\end{array} & \begin{array}{l}
\text { Tasa media de) }) \\
\text { arancel pagado }
\end{array} & \begin{array}{c}
\text { Valor total de }) \\
\text { exportaciones }
\end{array}
\end{array}
$$

Costo total de insumos intermedios por unidad de ventas totales 
La aplicación de la fórmula anterior estaría sujeta a la salvedad de que la devolución arancelaria no podría exceder el valor de los aranceles pagados. Es decir, cuando la aplicación de la fórmula descrita resulte en un valor mayor al del arancel pagado, sólo se devolverá éste último. De otra manera, cabría la posibilidad de que el esquema propuesto -que tiene por único objeto contrarrestar parcialmente el sesgo antiexportador que resulta de la protección al mercado interno- provocase la imposición de aranceles compensatorios, en perjuicio de nuestras exportaciones.

Con el fin de evitarle a los exportadores una carga financiera, los aranceles devueltos incluirían el pago de intereses. La tasa de interés podría ser la aprobada por el Congreso cada año para aplicarse en las disposiciones del Código Fiscal.

La administración del esquema propuesto no requeriría de un conocimiento técnico detallado y de una supervisión minuciosa de los artículos exportados y de las mermas incurridas en su producción. Por el contrario, para aplicarlo basta saber el valor de las ventas y el costo total de los insumos, los cuales se obtienen de la declaración del IVA. Ello favorecería un trámite más expedito de la importación, haciendo posible que las empresas más pequeñas, que frecuentemente son las que tienen menor capacidad administrativa, puedan aprovechar las ventajas del régimen de importación propuesto.

La incertidumbre respecto a la permanencia del régimen de importación temporal parece ser el factor más importante entre los que limitan un aprovechamiento más amplio. Reorientar la organización de la planta productiva hacia la exportación es, en muchos casos, un proceso prolongado y costoso que sólo se emprende cuando hay certidumbre acerca de la permanencia de la política comercial. Por eso, sería conveniente darle permanencia al nuevo régimen, haciéndolo irrevocable durante cierto número de años a partir del momento en que los exportadores se acojan a él.

El esquema propuesto presenta, adicionalmente, las siguientes ventajas:

a) Fomenta el cumplimiento del control de cambios, ya que la facilidad para importar estaría ligada al cumplimiento de los Compromisos de Venta de Divisas.

b) El sistema propuesto permitiría la importación de insumos libres de aranceles para empresas no exportadoras, que son, sin embargo, abastecedoras de los exportadores. 
3. Es importante insistir que tanto el esquema propuesto de tratamiento preferencial a las importaciones de las empresas exportadoras como el régimen vigente, no tienen como propósito primordial otorgar una ventaja neta a las exportaciones. Son, por el contrario, simplemente un medio para contrarrestar el sesgo anti-exportador que crea la protección comercial.

En el caso del régimen vigente de importación temporal, esta compensación es necesariamente parcial. Ello se explica por la siguiente razón. Si se hace caso omiso de las dificultades administrativas que entorpecen su funcionamiento, los exportadores pueden, en principio, bajo este régimen adquirir insumos intermedios en los mercados internacionales a los precios más bajos del mundo. De esta manera, se impide que el encarecimiento de los insumos intermedios -extranjeros y nacionalesderivado de la protección a las industrias que sustituyen importaciones reduzca la competitividad de los exportadores nacionales.

Sin embargo, la protección disminuye la rentabilidad relativa de la exportación al encarecer no sólo los precios de insumos intermedios nacionales que sustituyen importaciones, sino también los de aquellos insumos intermedios y factores productivos primarios que no pueden ser comerciados internacionalmente. Ello se debe a que las empresas protegidas tienen un poder de compra en los mercados de factores que no detentan las empresas no protegidas. El régimen actual de importación temporal, por definición, es incapaz de compensar los efectos sobre la exportación del encarecimiento de este tipo de insumos. En cambio, el régimen propuesto -como se mostrará más adelante- puede, bajo ciertas circunstancias, resultar más generoso que el actual. Ello constituye una ventaja muy importante, pues el margen adicional de devolución de aranceles permite contrarrestar el encarecimiento de los factores no comerciables que resulta de la protección. Por supuesto, en los casos en que el régimen actual resulte más generoso, los exportadores siempre contarán con la posibilidad de acogerse a éste, pues ambos esquemas coexistirían.

4. A continuación se presentan ejemplos numéricos que ilustran algunas de las implicaciones del régimen propuesto y que lo comparan con el vigente.

I. Efectos de cambios en la proporción de ventas de exportación en las ventas totales sobre el monto de devolución de aranceles. 
El siguiente cuadro describe la operación de una empresa que sólo utiliza insumos importados y que los requiere en proporciones iguales, para producir tanto para el mercado interno como para el extranjero

Empresa 1

\begin{tabular}{lccc}
\hline & $\begin{array}{c}\text { Producción para el } \\
\text { mercado interno }\end{array}$ & $\begin{array}{c}\text { Producción para el } \\
\text { mercado externo }\end{array}$ & TOTAL \\
\hline Insumos importados & 100 & 100 & 200 \\
Arancel Pagado & 10 & 10 & 20 \\
Insumos Nacionales & 0 & 0 & 0 \\
Valor Agregado & $\underline{200}$ & $\underline{200}$ & $\underline{400}$ \\
Valor de la producción & 310 & 310 & 620 \\
\hline
\end{tabular}

Aplicando la fórmula (2), el monto de los aranceles devueltos es de 11 pesos:

$\begin{array}{ccccccc}\begin{array}{c}\text { (Valor de }) \\ \text { exportaciones }\end{array} & \begin{array}{c}\text { (Arancel medio) } \\ \text { pagado }\end{array} & \times & \frac{(\text { Insumos totales }}{\text { ventas totales }} & = & \begin{array}{c}\text { Arancel) } \\ \text { devuelto }\end{array} \\ 310 & \mathrm{x} & 10 \% & \mathrm{x} & .355 & =11 \mathrm{pesos}\end{array}$

En este caso el monto de la devolución es muy similar al importe de los aranceles que una empresa no pagaría bajo el régimen actual de importación temporal. Bajo éste, el monto de los aranceles no pagados sería de 10 pesos, es decir, igual a los aranceles correspondientes a los insumos importados usados en la producción para exportación.

El siguiente ejemplo es similar al primero en varios aspectos: la empresa no utiliza insumos nacionales, tiene el mismo volumen total de ventas, y la proporción del costo de insumos a ventas es también de 35 por ciento tanto en la producción para exportación como en la producción para el mercado interno. La diferencia entre las empresas 1 y 2 radica en que la proporción de exportaciones a ventas totales es de 75 por ciento para la empresa 2 mientras que para la 1 es de 50 por ciento. 
Empresa 2

\begin{tabular}{lrrr}
\hline & $\begin{array}{c}\text { Producción para el } \\
\text { mercado interno }\end{array}$ & $\begin{array}{c}\text { Producción para el } \\
\text { mercado externo }\end{array}$ & TOTAL \\
\hline Insumos Importados & 50 & 150 & 200 \\
Arancel Pagado & 5 & 15 & 20 \\
Insumos Nacionales & 0 & 0 & 0 \\
Valor Agregado & 100 & 300 & 400 \\
Valor de la Producción & 155 & 465 & 620 \\
\hline
\end{tabular}

Aplicando la fórmula (2) para la determinación del monto de aranceles devueltos, la empresa 2 recibirá 16.51 pesos:

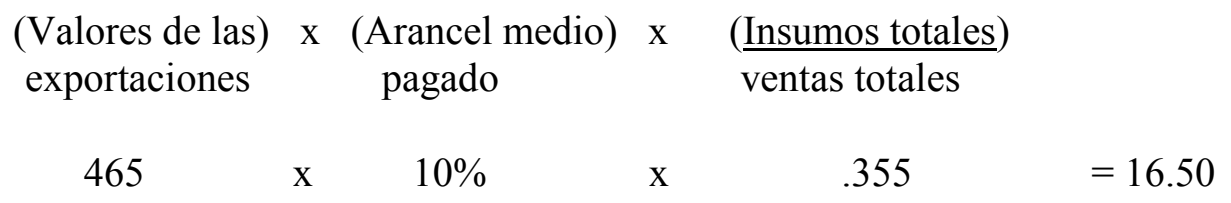

La devolución de aranceles para una empresa con ventas iguales a las de la empresa 1, pero que exporta una proporción de sus ventas 50 por ciento mayor, será también 50 por ciento mayor. Este ejemplo ilustra la característica fundamental del esquema propuesto: el beneficio fiscal es proporcional al porcentaje de exportaciones sobre ventas, dando un incentivo directo a la exportación ${ }^{*}$.

\footnotetext{
*/ Es posible, sin embargo, que bajo ciertas condiciones el beneficio fiscal total se reduzca al aumentar la proporción de las exportaciones en las ventas totales. En el Apéndice se describe la condición necesaria y suficiente para que al aumentar la proporción de exportaciones o ventas, se reduzca el beneficio fiscal como proporción del arancel pagado.
} 


\section{Cuadro 1}

Efectos sobre la devolución de aranceles de cambios

en la proporción de ventas de exportación a

ventas totales

\begin{tabular}{|c|c|c|c|c|c|}
\hline$\frac{\text { Exportaciones }}{\text { ventas totales }}$ & $\begin{array}{c}(1) \\
\text { Devolución } \\
\text { Teórica*/ }\end{array}$ & $\begin{array}{c}\text { (2) } \\
\text { Arancel } \\
\text { Pagado }\end{array}$ & $\begin{array}{c}\text { (3) } \\
\text { Devolución } \\
\text { Efectiva**/ }\end{array}$ & $\begin{array}{c}\text { (4) } \\
\text { Exención } \\
\text { Actual } \pm /\end{array}$ & $(3) /(4)$ \\
\hline 0 & $\$ 0$ & $\$ 20$ & $\$ 0$ & $\$ 0$ & \\
\hline .125 & 2.75 & 20 & 2.75 & 2.50 & 1.10 \\
\hline .25 & 5.50 & 20 & 5.50 & 5.00 & 1.10 \\
\hline .375 & 8.25 & 20 & 8.25 & 7.50 & 1.10 \\
\hline .5 & 11 & 20 & 11 & 10 & 1.10 \\
\hline .625 & 13.75 & 20 & 13.75 & 12.50 & 1.10 \\
\hline .75 & 16.50 & 20 & 16.50 & 15.00 & 1.10 \\
\hline .875 & 19.25 & 20 & 19.25 & 17.50 & 1.10 \\
\hline 1 & 22 & 20 & 20 & 20 & 1 \\
\hline
\end{tabular}

*/ Devolución Teórica $=$ Ecuación $(2)$

**/ $\begin{aligned} & \text { Devolución } \\ & \text { Efectiva }\end{aligned} \quad$ Ecuación (2) $\left\{\begin{array}{l}=\text { Ecuación (2) si } \\ =\text { Arancel Pagado si }\end{array} \quad\left\{\begin{array}{c}\text { MENOR QUE } \\ \text { MAYOR QUE }\end{array}\right\} \begin{array}{l}\text { Arancel } \\ \text { Pagado }\end{array}\right.$

\pm Exención Actual $=$ Ecuación $(1)$

1) Supuestos: $\quad$ Insumos Totales

$$
\text { Ventas Totales } \quad=.355
$$

$\begin{array}{ll}\text { Ventas } & =620 \\ \text { Arancel Promedio } & =10 \% \\ \text { Insumos Nacionales } & =0\end{array}$

Esta característica del esquema propuesto se ilustra en el Cuadro 1. En él se muestra como varía el monto de los aranceles devueltos al cambiar la proporción de las exportaciones con respecto a las ventas totales. Los cálculos de los que se derivan los resultados del Cuadro 1 suponen el mismo volumen de ventas totales que en el caso de las empresas 1 y 2 (620 pesos), una proporción idéntica de costos de insumos intermedios a ventas, tanto en la producción para exportación como en la producción para el mercado doméstico ( 35 por ciento), y que en ninguno de los dos casos se utilizan insumos 
nacionales. Nótese que, también en el régimen vigente el monto de la exención de aranceles aumenta proporcionalmente con el porcentaje de las ventas de exportación respecto a las ventas totales.

II. Efectos del uso de insumos nacionales sobre el monto de aranceles devueltos.

El siguiente cuadro se elaboró con cifras de una tercera empresa hipotética que es similar a la empresa 1 en dos aspectos: la proporción del costo de insumos a ventas totales es, al igual que en el primer caso, de 35 por ciento, y la proporción del valor de las ventas en el mercado interno a las ventas de exportación es nuevamente de uno a uno. La única diferencia entre las empresas 1 y 3 radica en que la tercera sí utiliza insumos nacionales. Más específicamente, utiliza una unidad de insumo nacional por cada unidad de insumo importado.

Empresa 3

\begin{tabular}{lrrr}
\hline & $\begin{array}{c}\text { Producción para el } \\
\text { mercado interno }\end{array}$ & $\begin{array}{c}\text { Producción para el } \\
\text { mercado externo }\end{array}$ & TOTAL \\
\hline Insumos Importados & 52.38 & 52.38 & 106.76 \\
Arancel Pagado & 5.23 & 5.23 & 10.47 \\
Insumos Nacionales & 52.38 & 52.38 & 104.76 \\
Valor Agregado & $\underline{200.00}$ & $\underline{200.00}$ & $\underline{400.00}$ \\
Valor de la Producción & $\underline{310.00}$ & 310.00 & 620.00 \\
\hline
\end{tabular}

Toda vez que los valores de las exportaciones, del arancel medio pagado y de la proporción de costos intermedios totales a ventas totales de la empresa 3 son iguales a los valores respectivos para la empresa 1, la aplicación de la fórmula propuesta arroja nuevamente un monto de 11 pesos. Siendo esta cantidad mayor que el arancel pagado, a la empresa se le devolverían únicamente 10.47 pesos. Nótese, sin embargo, que esta cantidad es mayor que el monto de los aranceles que la empresa no pagaría bajo un esquema como el vigente. En ese caso, la empresa dejaría de pagar únicamente 5.23 pesos, que es el valor del arancel correspondiente a los insumos importados incorporados en la producción para exportación.

El ejemplo muestra así otra característica general del esquema que se propone: en la medida en que se utilicen insumos intermedios nacionales para exportar, la relación de insumos intermedios totales por unidad de ventas totales tenderá a ser mayor que el coeficiente de insumos importados en las exportaciones. Por ello, en la medida en que se utilicen insumos intermedios nacionales para exportar, el esquema propuesto estimulará más las exportaciones que el vigente. 
El Cuadro 2 ilustra en forma más general esta propiedad del esquema propuesto. Dicho cuadro muestra como cambia el monto de los aranceles devueltos al variar la proporción de insumos nacionales a insumos importados, para una empresa con una proporción de costos intermedios totales a ventas totales y una proporción de ventas en el mercado interno a ventas de exportación iguales a las de las empresas 1 y 3 .

Destacan dos aspectos en los resultados del Cuadro 2:

(a) Dados los supuestos sobre la proporción de exportaciones a ventas internas y de la proporción de insumos totales a ventas totales, la aplicación del esquema propuesto (fórmula (2)) arroja siempre el mismo resultado (11 pesos), independientemente de cuál sea la proporción entre insumos nacionales e importados. Sin embargo, para empresas que

Cuadro $2^{1 /}$

Consecuencias sobre la devolución de aranceles de aumentar la proporción de los insumos intermedios nacionales

\begin{tabular}{|c|c|c|c|c|c|}
\hline $\begin{array}{l}\text { Insumos Nacionales } \\
\text { Insumos Importados }\end{array}$ & $\begin{array}{c}\text { (1) } \\
\text { Devolución } \\
\text { Teórica*/ }\end{array}$ & $\begin{array}{l}(2) \\
\text { Arancel } \\
\text { Pagado }\end{array}$ & $\begin{array}{c}\text { (3) } \\
\text { Devolución } \\
\text { Efectiva**/ }\end{array}$ & $\begin{array}{c}(4) \\
\text { Exención } \\
\text { Actual } \pm /\end{array}$ & (3)/(4) \\
\hline 0 & $\$ 11$ & $\$ 20.00$ & $\$ 11.00$ & $\$ 10.00$ & $\overline{1.10}$ \\
\hline .25 & 11 & 16.30 & 11.00 & 8.15 & 1.35 \\
\hline .5 & 11 & 13.75 & 11.00 & 6.88 & 1.60 \\
\hline .75 & 11 & 11.89 & 11.00 & 5.95 & 1.85 \\
\hline 1 & 11 & 10.48 & 10.48 & 5.24 & 2.00 \\
\hline 2 & 11 & 7.10 & 7.10 & 3.55 & 2.00 \\
\hline 5 & 11 & 3.61 & 3.61 & 1.80 & 2.01 \\
\hline 10 & 11 & 1.98 & 1.98 & .99 & 2.00 \\
\hline
\end{tabular}

*/ Devolución Teórica = Ecuación (2)

**/ Devolución $\begin{array}{lll}=\text { Ecuación (2) } & \text { si } \\ =\text { Arancel Pagado } & \text { si }\end{array} \quad$ Ecuación (2) $\left\{\begin{array}{l}\text { MENOR QUE } \\ \text { MAYOR QUE }\end{array}\right\} \begin{aligned} & \text { Arancel } \\ & \text { Pagado }\end{aligned}$

$\pm /$ Exención Actual $=$ Ecuación (1)

\begin{tabular}{ll}
\hline 1/ Supuestos: & $=1$ \\
$\frac{\text { Exportaciones }}{\text { Ventas Internas }}$ & $=.355$ \\
$\frac{\text { Insumos Totales }}{\text { Ventas Totales }}$ & $=620$ \\
Ventas Totales & $=10 \%$ \\
Arancel Promedio &
\end{tabular}


utilizan una proporción suficientemente elevada de insumos nacionales a insumos importados, el arancel pagado será inferior al que resulta de usar la fórmula (2). De ahí la importancia de la limitación que complementa la aplicación de la fórmula (2): a saber, que cuando la cantidad que resulte de aplicar dicha fórmula sea superior al monto de aranceles pagados, sólo se devolverán éstos. Por ello, en los ejemplos del Cuadro 1, cuando la relación de insumos nacionales a insumos importados es igual o mayor que uno, la devolución efectiva es menor que la devolución teórica, e igual al total de aranceles pagados.

(b) El esquema propuesto será más generoso que el vigente en la medida en, que aumente la proporción de insumos nacionales a insumos importados. Como se advierte en la última columna del Cuadro 2, el esquema propuesto otorga a las empresas que casi no utilizan insumos intermedios nacionales (esto es, a empresas del tipo de las maquiladoras) un tratamiento esencialmente idéntico que el del régimen actual. En cambio, a las empresas que utilizan también insumos nacionales, les proporciona un beneficio proporcionalmente mayor que el esquema vigente.

III. Efectos de diferencias en la tecnología de producción para la exportación y para el mercado interno sobre el monto de devolución de impuestos.

En los ejemplos examinados anteriormente se ha supuesto que la proporción de costos intermedios a ventas es la misma tanto en la producción para exportación como en la producción para el mercado interno. En este apartado se analizan los efectos que tienen sobre el monto de aranceles devueltos el hecho de que dicha proporción sea diferente en la producción destinada a cada uno de los dos mercados. 
El Cuadro siguiente ilustra la operación de la empresa 4:

Empresa 4

\begin{tabular}{lccc}
\hline & $\begin{array}{c}\text { Producción para el } \\
\text { mercado interno }\end{array}$ & $\begin{array}{c}\text { Producción para el } \\
\text { mercado externo }\end{array}$ & TOTAL \\
\hline Insumos Importados & 140.91 & 59.09 & 200 \\
Arancel Pagado & 14.09 & 5.91 & 20 \\
Insumos Nacionales & 0 & 0 & 0 \\
Valor Agregado & $\underline{155.00}$ & $\underline{245.00}$ & $\underline{400}$ \\
Valor de la Producción & 310.00 & 310.00 & 620 \\
\hline
\end{tabular}

Como puede advertirse, la empresa 4 es similar en varios aspectos a la empresa 1: no utiliza insumos intermedios nacionales, tiene el mismo volumen de ventas totales, la mitad de las mismas las destina al mercado interno y la mitad al mercado externo, y, finalmente, presenta la misma relación de costos intermedios totales a ventas totales. La empresa 4 es, sin embargo, diferente a la empresa 1 en un importante aspecto: mientras que la empresa 1 utiliza la misma tecnología para producir para los dos mercados, la producción de exportación de la empresa 4 es relativamente intensiva en valor agregado, y su producción para el mercado interno es relativamente intensiva en insumos.

Como el esquema propuesto se basa en la proporción de costos intermedios totales a ventas totales, la aplicación de la fórmula (2) da el mismo arancel a devolver que en el caso de la empresa 1 (es decir, 11 pesos):

(Valor de las)
exportaciones $\quad \begin{gathered}\text { (Arancel medio) } \\ \text { pagado }\end{gathered}$ 310 $\mathrm{x}$ $10 \%$ $\mathrm{X}$
Costos intermedios

$\begin{array}{cr}\frac{\text { totales }}{\text { Ventas totales }} & (\text { Arancel }) \\ \text { de vuelto } & \\ .355 & =11 \text { pesos }\end{array}$

Siendo este monto inferior al de los aranceles totales pagados (20 pesos), a la empresa 4 se le devolverán 11 pesos. El objeto del ejemplo es subrayar que este monto es superior al de la exención que resultaría de aplicar un régimen como el vigente. Bajo éste, la empresa 4 quedaría exenta del pago de aranceles únicamente por valor de 5.91 pesos, es decir, los aranceles correspondientes a las importaciones utilizadas en la producción para exportación. La discrepancia entre la devolución que resulta de cada uno de los dos esquemas se debe en este caso a que, dado que la empresa 4 usa diferentes tecnologías para producir para el mercado interno y para el externo, la proporción de costos intermedios totales a ventas totales en la cual se basa el esquema propuesto, no es un indicador fiel de 
la proporción de costos intermedios a ventas en la producción para exportación (en el ejemplo en cuestión, tiende a sobreestimarla). Es ésta una importante característica del régimen propuesto: a saber, que cuando la proporción de costos intermedios a ventas en la producción para exportación es menor que la proporción de costos intermedios totales a ventas totales, el esquema propuesto será más generoso que el régimen vigente, y viceversa.

\section{Cuadro $3 \frac{1}{} /$}

Efectos de diferencias en la tecnología de producción para la exportación y para el mercado interno sobre la devolución de aranceles

\begin{tabular}{cccccc}
\hline $\begin{array}{c}\text { Proporción de } \\
\text { costos } \\
\begin{array}{c}\text { intermedios a } \\
\text { ventas en la } \\
\text { exportación }\end{array}\end{array}$ & $\begin{array}{c}(1) \\
\text { Devolución } \\
\text { Teórica }\end{array}$ & $\begin{array}{c}(2) \\
\text { Arancel Pagado }\end{array}$ & $\begin{array}{c}(3) \\
\text { Devolución } \\
\text { Efectiva**/ }\end{array}$ & $\begin{array}{c}(4) \\
\text { Exención) } \\
\text { Actual+/ }\end{array}$ & $(3) /(4)$ \\
\hline 0 & $\$ 11$ & $\$ 20$ & $\$ 11$ & 0 & $\alpha$ \\
.1 & 11 & 20 & 11 & 2.82 & 3.90 \\
.2 & 11 & 20 & 11 & 5.64 & 1.95 \\
.3 & 11 & 20 & 11 & 8.45 & 1.30 \\
.355 & 11 & 20 & 11 & 10 & 1.10 \\
.4 & 11 & 20 & 11 & 11.27 & .98 \\
.5 & 11 & 20 & 11 & 14.09 & .78 \\
.6 & 11 & 20 & 11 & 16.91 & .65 \\
.7 & 11 & 20 & 11 & 19.73 & .56 \\
\hline
\end{tabular}

*/ Devolución Teórica $=$ Ecuación (2)

**/ $\begin{aligned} & \text { Devolución } \\ & \text { Efectiva }\end{aligned}\left\{\begin{array}{l}=\text { Ecuación (2) si } \\ =\text { Arancel Pagado si }\end{array}\right.$ Ecuación (2) $\left\{\begin{array}{l}\text { MENOR QUE } \\ \text { MAYOR QUE }\end{array}\right\} \begin{aligned} & \text { Arancel } \\ & \text { Pagado }\end{aligned}$

$\pm /$ Exención Actual $=$ Ecuación $(1)$

1/ Supuestos: $\quad$ Exportaciones $\quad=1$

Ventas Internas

$\underline{\text { Insumos Totales }} \quad=.355$

Ventas Totales

$=620$

Ventas Totales

$=10 \%$

Arancel Promedio

$=0$ 
Esta propiedad es ilustrada en forma más general por el Cuadro 3, que muestra como cambia la devolución de aranceles para una proporción dada de costos intermedios a ventas totales (en este caso igual a .355), cuando se modifica la proporción de costos intermedios a ventas en la producción para exportación. Como puede advertirse en la última columna del cuadro, cuando la proporción para exportación es relativamente intensiva en valor agregado y la producción para el mercado interno es relativamente intensiva en el uso de insumos importados, el esquema propuesto tiende a ser mucho más generoso que el régimen actual. En el caso extremo (descrito en el primer renglón) en el que no se emplean insumos importados en la producción de exportación no se exentaría a la empresa del pago de aranceles en el régimen vigente, porque los insumos que importa son utilizados únicamente en la producción que vende internamente. En cambio, el esquema propuesto, al no identificar físicamente el destino de los insumos importados, sí le concedería un beneficio fiscal a la empresa. Así, en el Cuadro 3, a medida que las características de las tecnologías de la producción para la exportación y la producción para ventas internas se invierten, la generosidad relativa del esquema propuesto respecto al régimen se reduce y eventualmente se vuelve inferior. Aunque la posibilidad de que una situación así se presente no puede descartarse a priori, cabe adelantar la conjetura de que, en general, los factores que tienden a hacer que el régimen propuesto sea más generoso que el vigente -esencialmente, el uso de insumos intermedios nacionales- tenderán a ser empíricamente más importantes que los que lo harían menos generoso (es decir, la existencia de diferentes tecnologías en la producción de exportación y en la producción para el mercado interno). En cualquier caso, las empresas siempre contarían con la opción de acogerse al régimen vigente si les resulta más conveniente. 


\section{APÉNDICE}

Los efectos de la aplicación del esquema propuesto se pueden generalizar a partir de la fórmula (2). Expresando esta última en términos de sus distintos componentes tenemos:

$$
\mathrm{A}=\mathrm{t} \cdot \mathrm{x}\left(\underline{\mathrm{N}}_{\underline{\mathrm{d}}+\mathrm{N}_{\mathrm{x}}+\left(\mathrm{I}_{\underline{\mathrm{d}}}+\mathrm{I}_{\underline{x}}\right) 1+\mathrm{t}}^{\mathrm{X}+\mathrm{D}}\right.
$$

donde:

A : arancel devuelto,

$\mathrm{t}$ : $\quad$ tasa media de arancel pagado,

$\mathrm{X}$ : valor de las exportaciones,

$\mathrm{N}_{\mathrm{d}}$ : valor de los insumos nacionales usados en las ventas domésticas,

$\mathrm{N}_{\mathrm{x}}$ : valor de los insumos nacionales usados en las exportaciones,

$I_{d}$ : valor de los insumos importados usados en las ventas domésticas (neto de aranceles),

$\mathrm{I}_{\mathrm{x}}$ : valor de los insumos importados usados en las exportaciones (neto de aranceles),

D : valor de las ventas domésticas.

La fórmula (3) puede ser expresada también como:

(4) $\quad \frac{\mathrm{A}}{\mathrm{V}}=\mathrm{t} \cdot \mathrm{p}\left[\mathrm{p}(1+\mathrm{t})\left(\mathrm{I}_{\mathbf{x}}-\mathrm{I}_{\mathbf{d}}\right)+\mathrm{p}\left(\mathrm{n}_{\mathbf{x}}-\mathrm{n}_{\mathrm{d}}\right)+(1+\mathrm{t}) \mathrm{I}_{\mathbf{d}}+\mathrm{n}_{\mathbf{d}}\right]$

donde:

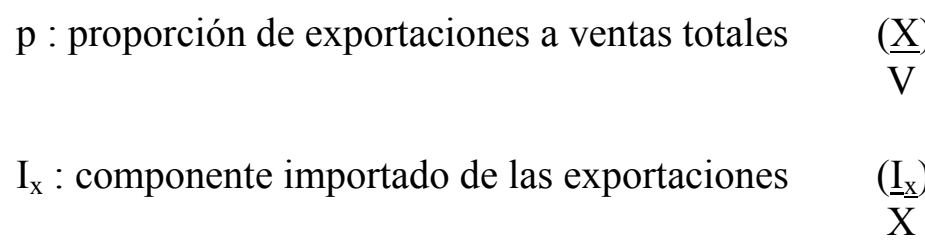

$I_{d}$ : componente importado de las ventas domésticas $\left(\underline{I}_{d}\right)$

D

$\mathrm{n}_{\mathrm{X}}$ : componente nacional de las exportaciones $\quad\left(\underline{\mathrm{N}_{\underline{\mathrm{X}}}}\right)$

$\mathrm{n}_{\mathrm{d}}$ : componente nacional de las ventas domésticas $\quad\left(\underline{\mathrm{N}}_{\mathrm{d}}\right)$

$\mathrm{D}$

además:

$\mathrm{va}_{\mathrm{X}}$ : valor agregado por peso exportado 
$\mathrm{va}_{\mathrm{d}}$ : valor agregado por peso de ventas internas.

$\mathrm{C}_{\mathrm{t}}$ : proporción de costos intermedios totales a. Ventas totales $\left(\underline{\mathrm{I}}_{\underline{\mathrm{d}}}+\underline{\mathrm{I}}_{\underline{\mathrm{x}}}+\mathrm{N}_{\mathrm{X}} \underline{\mathrm{D}}+\mathrm{N}_{\mathrm{d}_{-}}\right)$

$\mathrm{C}_{\mathrm{X}}$ : proporción de costos intermedios a ventas en la producción de exportación $\left(\frac{\mathrm{I}_{\underline{x}}+\mathrm{N}_{\mathrm{x}}}{\mathrm{X}}\right)$

$\mathrm{C}_{\mathrm{d}}$ : proporción de costos intermedios a ventas en la producción para el mercado interno $\left(\mathrm{I}_{\underline{\mathrm{d}}}+\mathrm{N}_{\mathrm{d}}\right)$

La expresión (4) pone de manifiesto la relación entre el monto de aranceles devueltos y los factores que se analizaron anteriormente en los ejemplos numéricos. Así, de la ecuación (4) resulta que el monto de aranceles devueltos será mayor:

I. mientras mayor sea la intensidad absoluta en el uso de insumos importados en las exportaciones $\left(\mathrm{I}_{\mathrm{x}}\right)$;

II. mientras mayor sea la intensidad absoluta en el uso de insumos nacionales en las exportaciones $\left(\mathrm{n}_{\mathrm{x}}\right)$;

III. mientras mayor sea la intensidad absoluta en el uso de insumos importados en la producción para el mercado interno $\left(I_{d}\right)$ y

IV. mientras mayor sea la intensidad absoluta en el uso de insumos nacionales de la producción para el mercado interno $\left(\mathrm{n}_{\mathrm{d}}\right)$.

El análisis del efecto sobre el monto de aranceles devueltos de un aumento de la proporción de las ventas totales que se destina a la exportación (p) es más complejo. Dicho efecto será positivo siempre que se cumpla la siguiente condición:

(5) $\mathrm{va}_{\mathrm{x}} \quad \underline{\text { MENOR QUE }} \mathrm{va}_{\mathrm{d}}+\frac{(1+\mathrm{t}) \mathrm{I}_{\mathrm{d}}+\mathrm{n}_{\mathrm{d}}}{2 \mathrm{p}}$ y será negativo en case contrario.

Para comprender el significado de la condición (5) resulta útil analizar el comportamiento de la proporción de costos intermedios totales a ventas totales $\left(\mathrm{c}_{\mathrm{t}}\right)$ (de la cual depende positivamente el valor de los aranceles devueltos en el esquema propuesto) como función de la proporción exportada (p). 
Recuérdese que, por definición de valor agregado, se cumple que

(6) $\quad v a_{x}=1-c_{x}$

(7) $\quad \mathrm{va}_{\mathrm{d}}=1-\mathrm{c}_{\mathrm{d}}$

y por definición de costos intermedios totales:

(8) $\quad c_{t}=p c_{x}+(1-p) c_{d}$

Combinando las ecuaciones (6), (7) y (8) se obtiene una expresión para $c_{t}$ en términos de $\mathrm{va}_{\mathrm{x}} \mathrm{y}$ $v a_{d}:$

(9) $\quad c_{t}=\left(1-v a_{d}\right)+p\left(v a_{d}-v a_{x}\right)$

Las gráficas 1 y 2 describen la forma en que, de acuerdo a la ecuación (9), varía $c_{t}$ al variar la proporción exportada $\mathrm{p}$ :

\section{Gráfica 1}

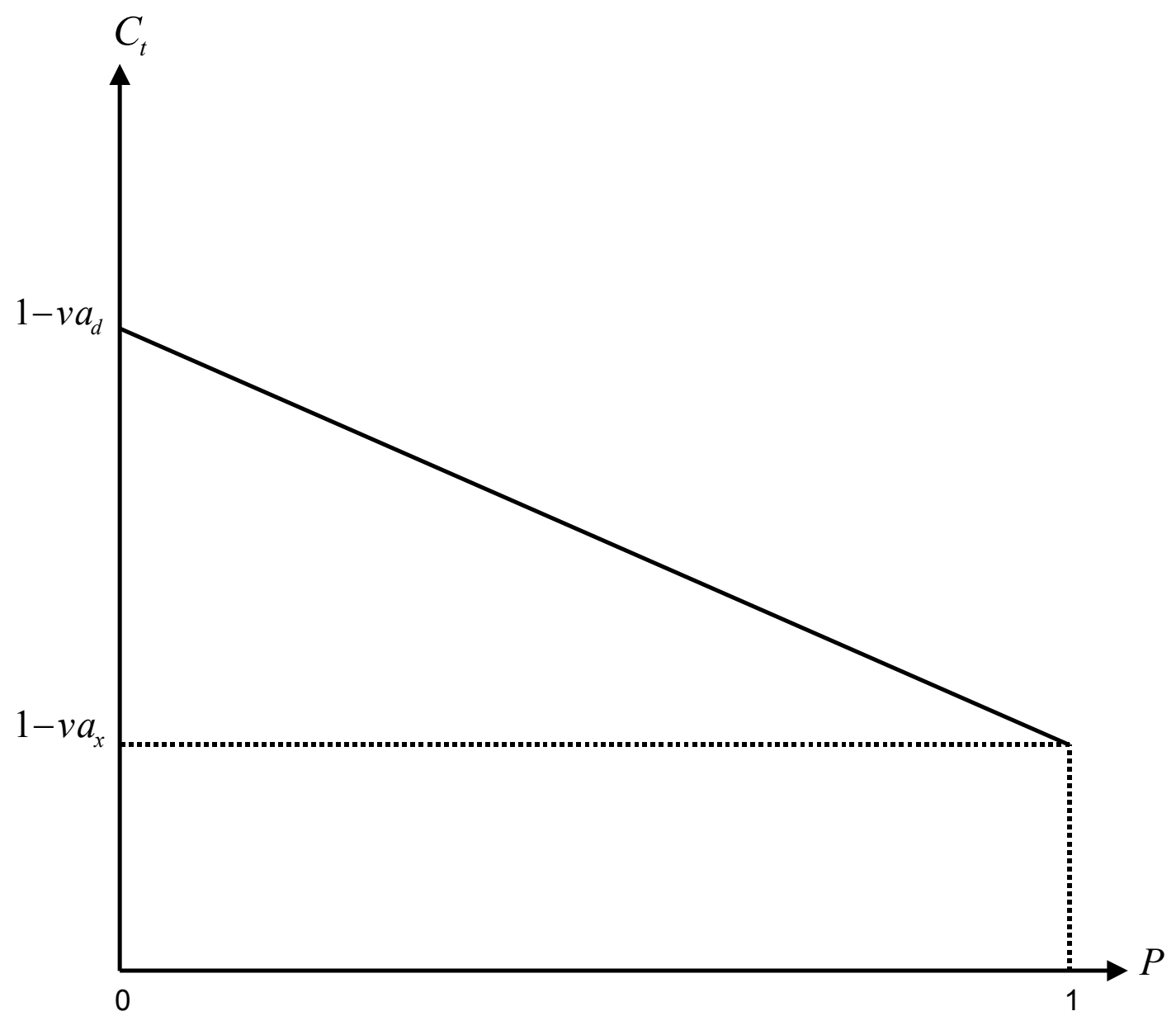




\section{Gráfica 2}

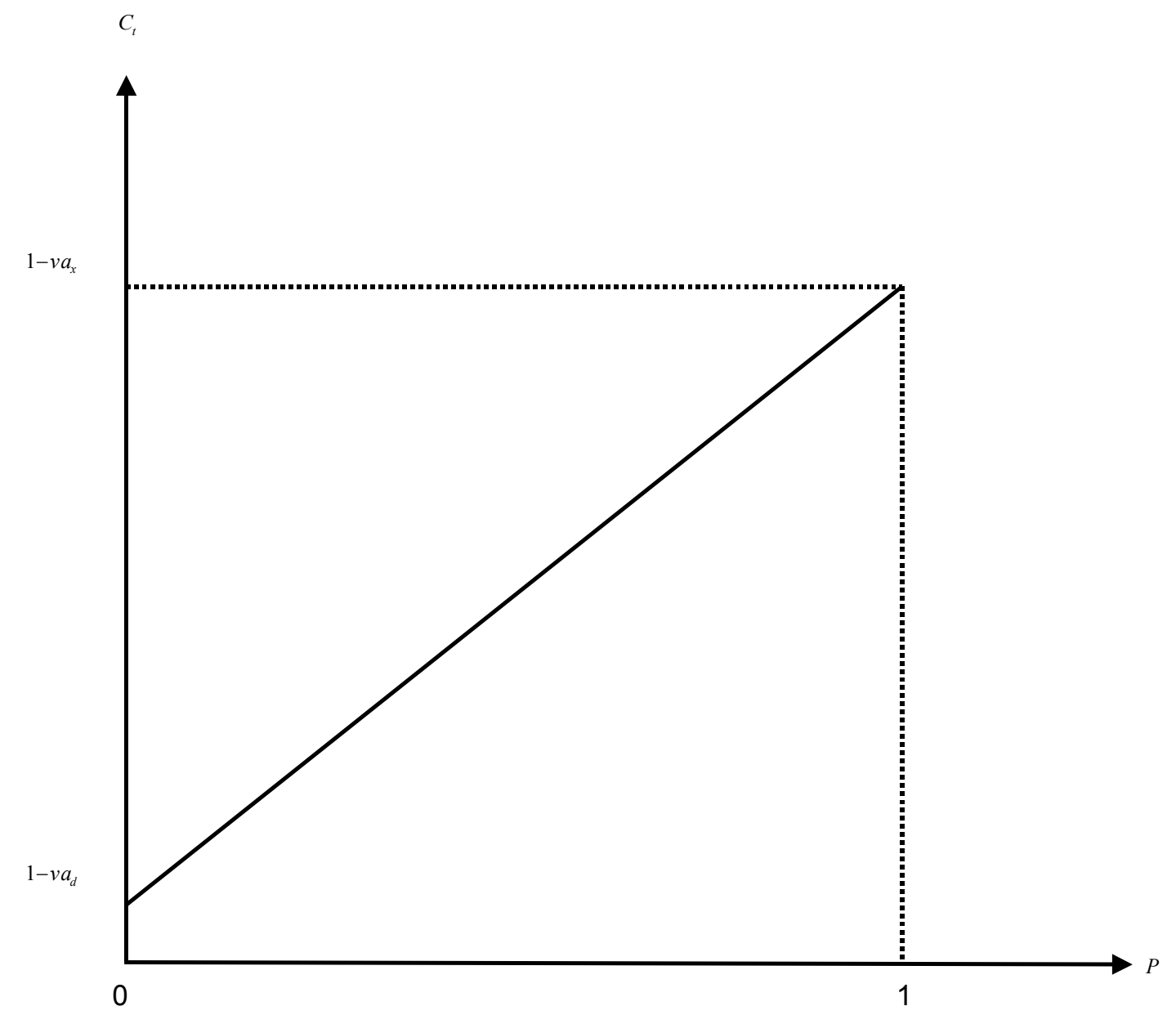

De acuerdo a (8), la proporción de costos intermedios totales $\left(\mathrm{c}_{\mathrm{t}}\right)$ es un promedio ponderado de la proporción de costos intermedios en las ventas de exportación $\left(\mathrm{c}_{\mathrm{x}}\right) \mathrm{y}$ en las ventas internas $\left(\mathrm{c}_{\mathrm{d}}\right)$, donde las ponderaciones son p y (1-p), respectivamente. En consecuencia, si, como sucede en la Gráfica 2, va $\mathrm{x}_{\mathrm{x}}$ es menor que $\mathrm{va}_{\mathrm{d}}$-lo cual implica que $\mathrm{c}_{\mathrm{x}}$ es mayor que $\mathrm{c}_{\mathrm{d}^{-}}$al aumentar $\mathrm{p}$ aumentará también $c_{t} \mathrm{y}$ mayor tenderá a ser el arancel devuelto en el esquema propuesto. De ahí que sea necesario (y suficiente) que se cumpla la condición (5) para que el monto de aranceles devueltos esté positivamente relacionado con la proporción exportada $(\mathrm{p})$.

Nótese, por otra parte, que el valor agregado por unidad de exportación $\left(\mathrm{va}_{\mathrm{x}}\right)$ puede ser mayor que el valor agregado por unidad de ventas internas $\left(\mathrm{va}_{\mathrm{d}}\right)$ sin que ello necesariamente implique que un aumento de la proporción exportada de las ventas totales reducirá el monto de aranceles devueltos, y que para valores suficientemente pequeños de la proporción exportada p, la condición (5) necesariamente se cumplirá. Es posible, asimismo, que aún cuando la condición (5) no se cumpla (de 
manera que el monto de aranceles devueltos disminuya al aumentar la proporción p), la generosidad

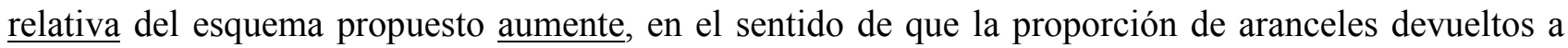
aranceles pagados se incremente al crecer p.*

Las gráficas que se presentan a continuación permiten ilustrar los resultados anteriores. En todas las gráficas, en el eje vertical aparece la razón de arancel devuelto a ventas, y en el eje horizontal la participación de las exportaciones en las ventas totales. Las gráficas comparan la proporción de aranceles devueltos a ventas que resulta de aplicar el esquema propuesto con la proporción de aranceles pagados a ventas que resulta del esquema vigente bajo distintos valores de los parámetros de la fórmula (4). Cabe hacer notar que en algunos de los casos presentados a continuación, las funciones graficadas se vuelven horizontales a partir de aquella razón de exportaciones a ventas totales para la cual el arancel devuelto es igual al arancel pagado. Ello se debe a que bajo el esquema propuesto la devolución arancelaria no puede exceder el pago de aranceles inicial.

La Gráfica 3 ilustra el efecto de cambios en los requerimientos de insumos importados de las exportaciones $\left(I_{x}\right)$. En términos de la ecuación (4), esto significa cambios en el coeficiente $\left(I_{x}-I_{d}\right)$ manteniendo los parámetros $\mathrm{I}_{\mathrm{d}}, \mathrm{n}_{\mathrm{d}} \mathrm{y} \mathrm{n}_{\mathrm{x}}$ constantes. Dado que por definición se cumplen las ecuaciones (6) y (7), la contrapartida del aumento en $I_{x}$ es una disminución en va $a_{x}$ (De manera similar, en los ejemplos que se analizan más adelante, $\mathrm{va}_{\mathrm{x}} \mathrm{o} \mathrm{va}_{\mathrm{d}}$ se ajustan ante los cambios en los parámetros analizados de tal manera que las restricciones (6) y (7) se cumplan).

Como se puede apreciar en la gráfica 3, tanto en el régimen propuesto como en el actual, un incremento en el uso de insumos importados en las exportaciones, implica un tratamiento arancelario más favorable. No obstante, en todos los casos el incentivo resultante del esquema propuesto es mayor,

*! Ello ocurriría si la condición (5) no se cumple, pero

(6) $v a_{x}$ MENOR QUE $v a_{d}+\frac{(1+t) i_{d}+n_{d}}{2_{p}} \bullet \frac{i_{d}}{i_{d}+(p / 2)\left(i_{x}-i_{d}\right)}$

Evidentemente, si la condición (5) no se cumple, para que se satisfaga la condición (6) es necesario (pero no suficiente) que $I_{d}>I_{x}$, de tal manera que, el segundo factor del segundo término de la expresión de la derecha en (6) sea mayor que uno. Siendo en ese caso la producción para el mercado interno relativamente más intensiva en el uso de insumos importados, al aumentar la proporción exportada p, el monto total de aranceles pagados disminuirá. 
pues la devolución es función de la participación de todos los insumos en las ventas, y no sólo, como sucede con el régimen vigente, del componente importado de las exportaciones.

\section{Gráfica 3}

Efectos de los Cambios en el Componente Importado de las Exportaciones $\left(\mathrm{i}_{\mathrm{x}}\right)$ sobre el Arancel Devuelto

$$
\left(\mathrm{i}_{\mathrm{d}}=.50, \mathrm{n}_{\mathrm{x}}=.20, \mathrm{n}_{\mathrm{d}}=.20, \mathrm{t}=.10\right)
$$

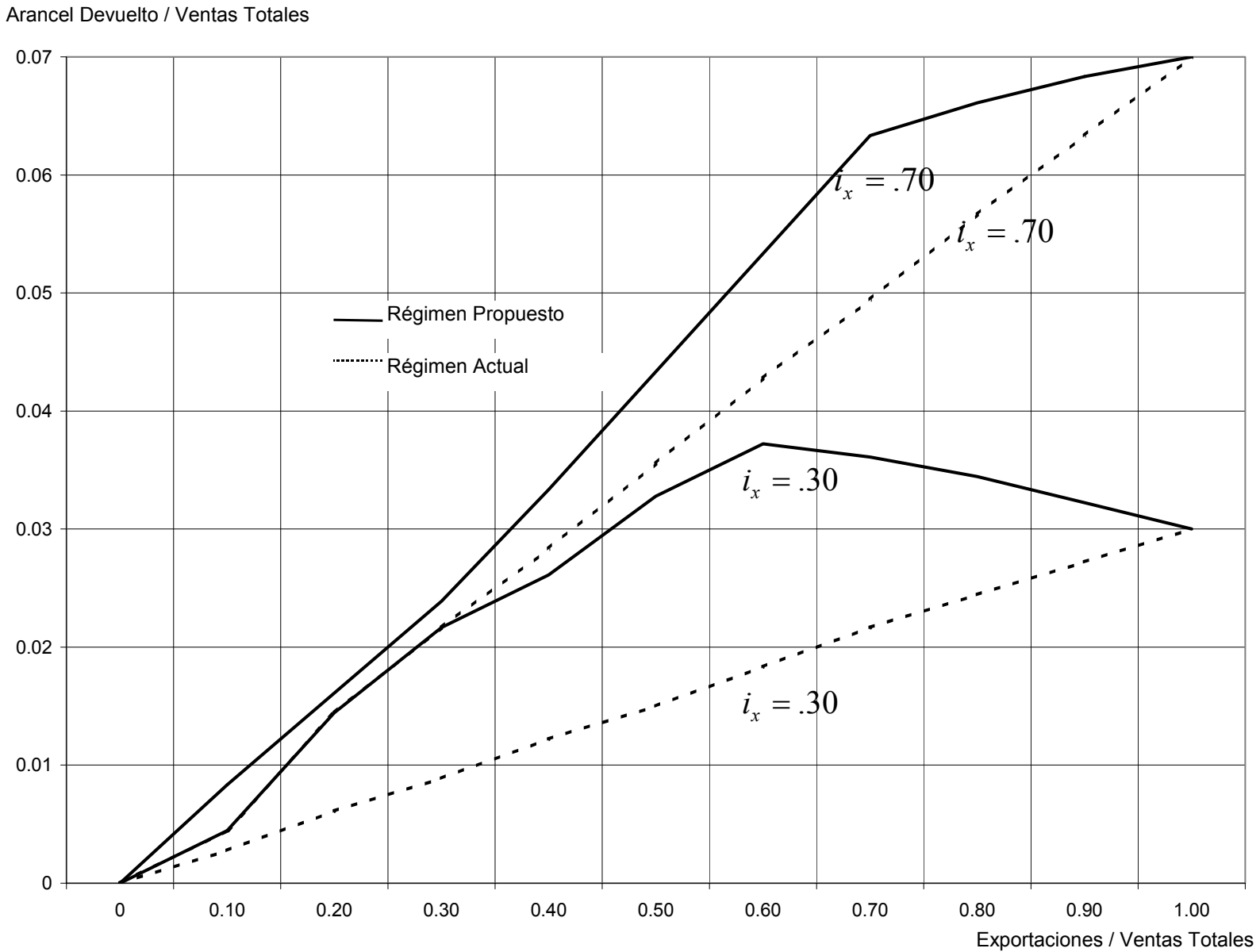

Cabe hacer notar que las funciones correspondientes al esquema propuesto no son siempre crecientes. Mientras que en el caso en el que $\mathrm{I}_{\mathrm{x}}=0.70$, el arancel devuelto es una función creciente de la participación de las exportaciones en las ventas totales, cuando $\mathrm{I}_{\mathrm{x}}=0.30$, el arancel devuelto alcanza un valor máximo cuando las exportaciones representan el $60 \%$ de la producción total y empieza a disminuir a partir de ese punto. La explicación de este comportamiento es la siguiente: en el primer caso, las exportaciones son relativamente más intensivas en insumos intermedios (en particular en insumos importados, pues $I_{x}>I_{d}$ y $n_{x}=n_{d}$ ), por lo que un aumento de las ventas al exterior se traduce en una mayor participación del costo de los insumos intermedios en las ventas totales. En el segundo 
caso, en cambio, sucede el fenómeno inverso. Puesto que las exportaciones son relativamente intensivas en valor agregado, al aumentar su participación (p) más allá de cierto nivel, el arancel devuelto tenderá a decrecer pues la proporción de costos intermedios totales a ventas totales disminuirá.

La Gráfica 4 ilustra los efectos de cambios en el uso de insumos nacionales en la producción para la exportación $\left(\mathrm{n}_{\mathrm{x}}\right)$.

En este caso, bajo el régimen actual la razón de aranceles no pagados a ventas como función de la proporción $\mathrm{p}$ no cambia al modificarse $\mathrm{n}_{\mathrm{x}}$ pues el componente importado de las exportaciones permanece constante en todos los casos $\left(\mathrm{I}_{\mathrm{x}}=.50\right)$. Bajo el esquema propuesto, por el contrario, la mencionada función sí cambia, pues al elevarse el requerimiento de insumos nacionales de las exportaciones, se incrementa el valor total de los insumos intermedios, y con ello el arancel devuelto.

La Gráfica 5 ilustra el efecto de cambios en el componente importado de las ventas internas $\left(\mathrm{I}_{\mathrm{d}}\right)$. Una vez más, en la medida en que aumenta el uso de insumos intermedios, el monto de aranceles devueltos como función de p se vuelve más favorable bajo el esquema propuesto. La función de exención arancelaria bajo el régimen vigente, por el contrario, no se modifica al no haber cambios en el uso de insumos importados en la producción de exportaciones. Nótese que bajo el esquema propuesto, 


\section{Gráfica 4}

Efectos de Cambios en el Componente Nacional de las Exportaciones $\left(\mathrm{n}_{\mathrm{x}}\right)$ sobre el Arancel Devuelto

$$
\left(\mathrm{i}_{\mathrm{d}}=.50, \mathrm{i}_{\mathrm{p}}=.20, \mathrm{n}_{\mathrm{d}}=.20, \mathrm{t}=.10\right)
$$

Arancel Devuelto / Ventas Totales

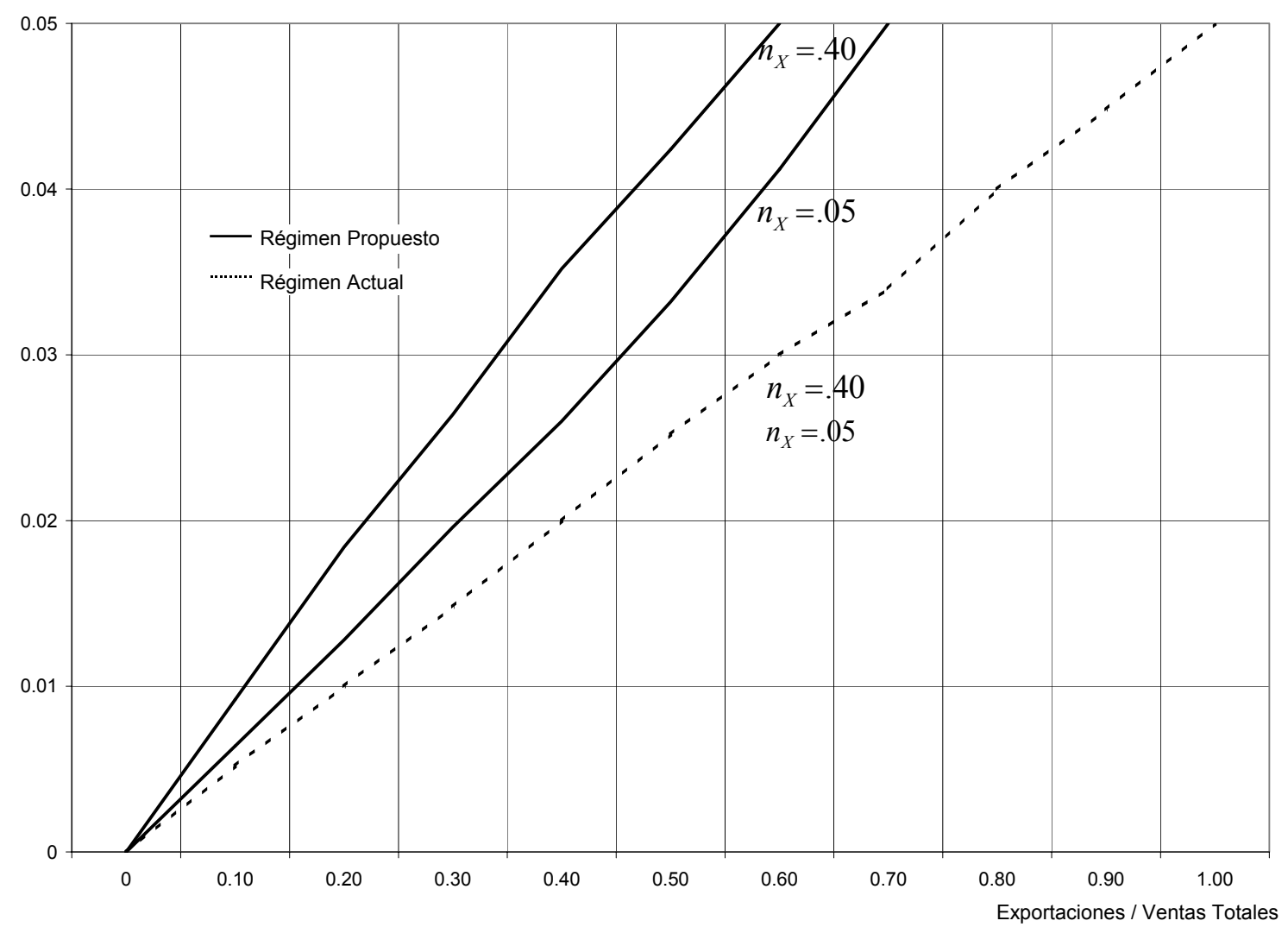




\section{Gráfica 5}

Efectos de los Cambios en el Componente Importado de los Productos Vendidos Internamente $\left(\mathrm{i}_{\mathrm{d}}\right)$ sobre el Arancel Devuelto

$$
\left(\mathrm{i}_{\mathrm{x}}=.50, \mathrm{n}_{\mathrm{x}}=.20, \mathrm{n}_{\mathrm{d}}=.20, \mathrm{t}=.10\right)
$$

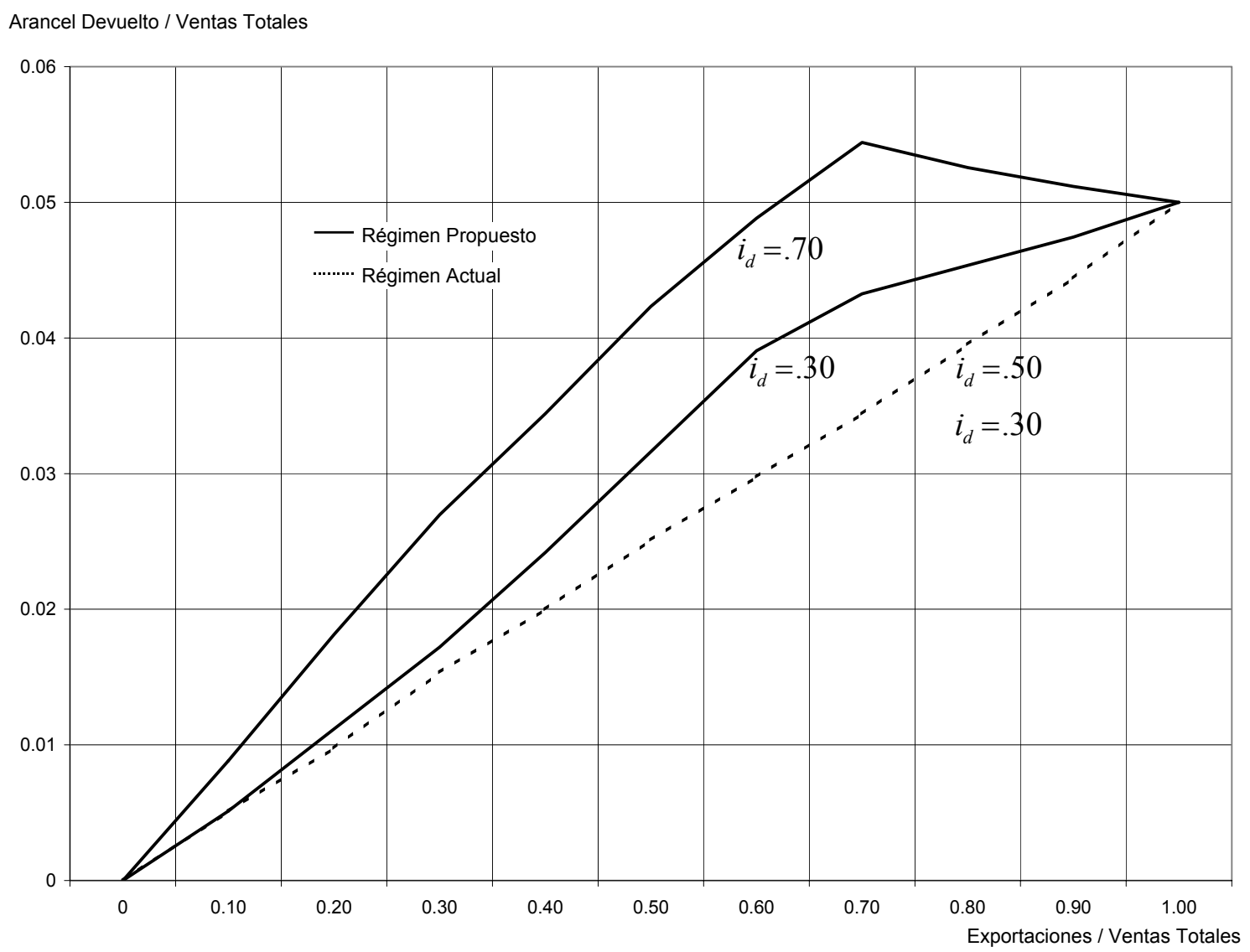

entre mayor sea $I_{d}$, más rápidamente empezará a declinar el arancel devuelto al expandirse las exportaciones, porque la razón de costos intermedios totales a ventas totales disminuye. Es posible, sin embargo, que la razón de aranceles devueltos a aranceles pagados aumente en el caso en que $\mathrm{I}_{\mathrm{d}}=.70$. Esto es así porque las exportaciones son relativamente más intensivas en valor agregado y menos intensivas en insumos importados $\left(I_{d}>I_{x}\right.$ y $\left.n_{x}=n_{d}\right)$.

Por último, la gráfica 6 ilustra el efecto de un cambio en los requerimientos de insumos nacionales de los productos vendidos internamente. Un aumento en el uso de insumos nacionales para la producción destinada al mercado interno se traduce en un tratamiento arancelario más favorable bajo el esquema propuesto. Esto se debe, una vez más, a que se incrementa el costo total de los insumos intermedios como proporción del valor de las ventas. El esquema de devolución arancelaria vigente, 
por el contrario, permanece constante, al no haber cambio en el componente importado de las exportaciones.

\section{Gráfica 6}

Efectos de los Cambios en el Componente Interno de las Ventas Internas $\left(\mathrm{n}_{\mathrm{d}}\right)$ sobre el Arancel Devuelto

$$
\left(\mathrm{i}_{\mathrm{x}}=.50, \mathrm{i}_{\mathrm{d}}=.20, \mathrm{n}_{\mathrm{x}}=.20, \mathrm{t}=.10\right)
$$

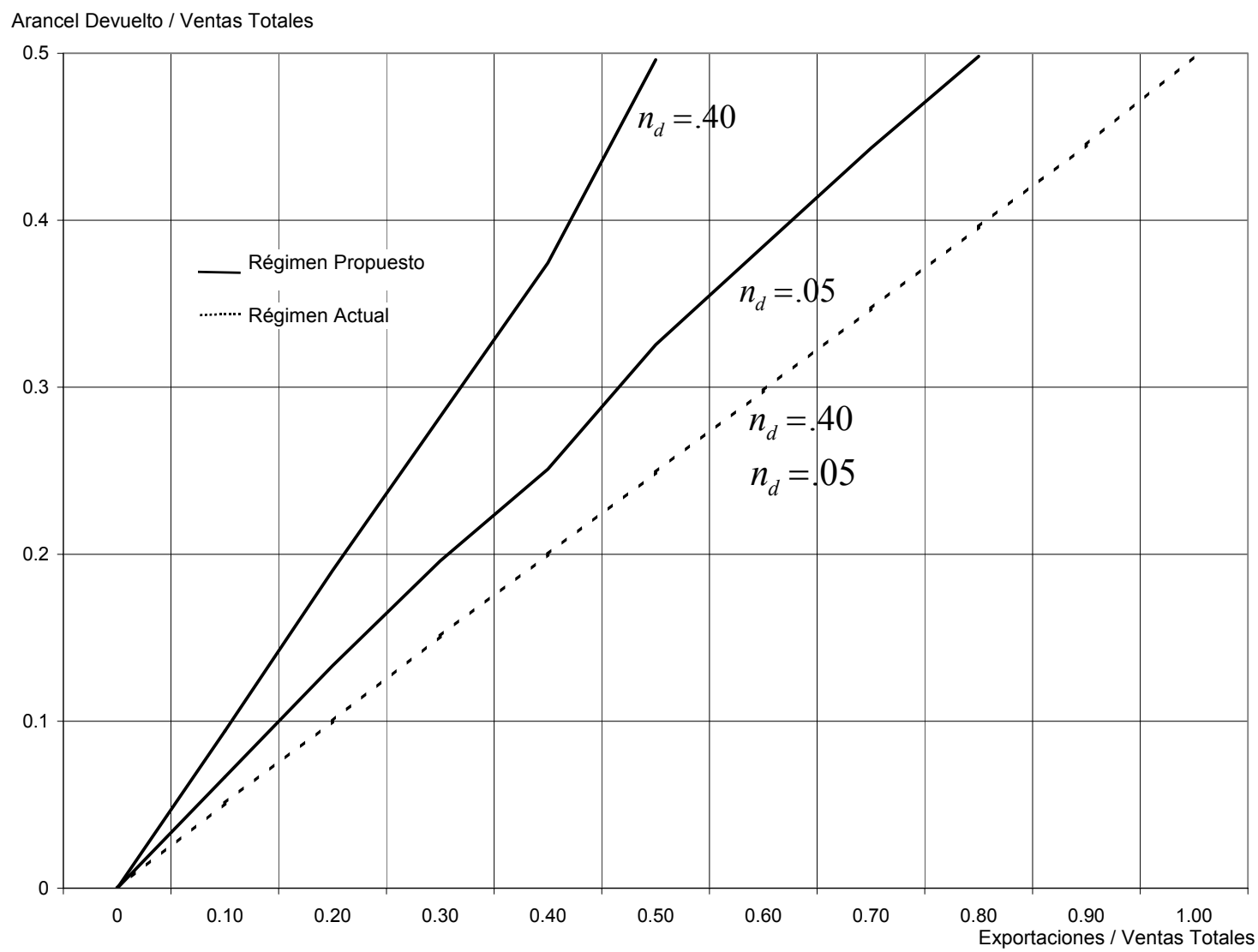




\section{BANCO DE MÉXICO \\ SUBDIRECCIÓN DE INVESTIGACIÓN ECONÓMICA}

Serie de Documentos de Investigación

1. ESTRUCTURA FINANCIERA Y EXPERIENCIA CAMBIARIA: MÉXICO 1954-1977. Guillermo Ortiz. Octubre, 1978.

2. EL FINANCIAMIENTO DEL GASTO PUBLICO EN UNA ECONOMÍA EN CRECIMIENTO: EL CASO DE MÉXICO.

Alain Ize. Noviembre, 1978.

3. ALGUNOS ASPECTOS DEL ENDEUDAMIENTO PUBLICO EXTERNO EN MÉXICO. Ernesto Zedillo. Diciembre, 1978.

4. UNA APLICACIÓN: DEL MODELO BAYESIANO DE DECISIÓN EN EL ANÁLISIS DE FUNCIONES DE PRODUCCIÓN AGRÍCOLA.

Héctor E. González M. Diciembre, 1978.

5. POLÍTICA MACROECONOMICA EN EL CORTO PLAZO: UNA RESEÑA.

Alain Ize. Marzo, 1979.

6. ESTUDIOS DE MONEDA Y BANCA Y POLÍTICA MONETARIA SOBRE MÉXICO: SELECCIÓN BIBLIOGRÁFICA DE 1943 A 1978.

Abril, 1979.

7. COMERCIO EXTERIOR MÉXICO-ESTADOS UNIDOS: PROBLEMAS DE COMPARABILIDAD ESTADÍSTICA.

Jorge Carriles Rubio. Mayo, 1979.

8. EXPLOTACIÓN OPTIMA DE RESERVAS PETROLERAS EN UN CONTEXTO MACROECONOMICO.

José Córdoba. Mayo, 1979.

9. ASPECTOS DEFLACIONARIOS DE LA DEVALUACIÓN DEL PESO MEXICANO DE 1976. José Córdoba y Guillermo Ortiz. Mayo, 1979.

10. EXTRACCIÓN OPTIMA DE PETRÓLEO Y ENDEUDAMIENTO EXTERNO: EL CASO DE MÉXICO.

Ernesto Zedillo. Junio, 1979.

11. IMPUESTOS DIRECTOS: PROGRESIVIDAD OPTIMA.

Jesús Seade. Septiembre, 1979.

12. OPCIONES DE POLÍTICA ECONÓMICA 1979-1982.

Sócrates Rizzo y Leopoldo Solís. Septiembre, 1979 
13. INTERMEDIARIOS FINANCIEROS Y MERCADOS IMPERFECTOS DE CAPITAL. Guillermo Ortiz. Septiembre, 1979.

14. ESTIMACIONES DE EQUILIBRIO GENERAL DE LOS EFECTOS DE LAS DISTORSIONES EN LOS MERCADOS DE FACTORES: EL CASO DE MÉXICO.

José J. Sidaoui y Richard H. Sines. Octubre, 1979.

15. UN ANÁLISIS DE LA INFLACIÓN EN MÉXICO.

Alain Ize. Octubre, 1979.

16. ANÁLISIS DE LOS COMPONENTES DEL CAMBIO ESTRUCTURAL CON UN MODELO DE EQUILIBRIO GENERAL, 1970-75.

José J. Sidaoui y Richard H. Sines. Enero, 1980.

17. TIPOS DE CAMBIO FLOTANTES Y DESLIZ CAMBIARIO: LAS EXPERIENCIAS DE ALGUNOS PAÍSES EN DESARROLLO.

Guillermo Ortiz y Leopoldo Solís. Enero, 1980.

18. UN MODELO DE INFLACIÓN Y CRECIMIENTO EN UNA ECONOMÍA CAPITALISTA EN DESARROLLO.

Alain Ize. Enero, 1980.

19. CRECIMIENTO E INFLACIÓN: ALTERNATIVAS CAMBIARIAS PARA MÉXICO. Guillermo Ortiz y Leopoldo Solís. Febrero, 1980.

20. COMPORTAMIENTO DE LA CAPTACIÓN BANCARIA EN MÉXICO.

Héctor E. González Méndez. Mayo, 1980.

21. LA ENCUESTA DE TURISMO RECEPTIVO. REPORTE METODOLOGICO.

Alberto Vargas Aguayo. Junio, 1980.

22. AJUSTE ESTACIONAL DE UNA SERIE DE TIEMPO MEDIANTE EL USO COMPLEMENTARIO DE MÉTODOS TRADICIONALES Y LA TÉCNICA DE BOXJENKINS.

Gabriel Vera Ferrer y Víctor M. Guerrero. Julio, 1980.

23. DISTRIBUCIÓN DEL FINANCIAMIENTO OTORGADO POR EL SISTEMA BANCARIO MEXICANO A LA BANCA PRIVADA Y MIXTA.

Víctor M. Guerrero y Gabriel Vera Ferrer. Julio, 1980.

24. LA MIGRACIÓN INDOCUMENTADA A ESTADOS UNIDOS: UN NUEVO ENFOQUE. Juan Díez Canedo. Julio, 1980.

25. UN MODELO FINANCIERO DE DESEQUILIBRIO A CORTO PLAZO PARA LA ECONOMÍA MEXICANA.

Alain Ize. Julio, 1980. 
26. ESTIMACIÓN DE LA FUNCIÓN DE IMPORTACIONES PARA MÉXICO. Javier Salas. Agosto, 1980.

27. UNA ALTERNATIVA PARA LA MEDIA ARITMÉTICA EN EL CALCULO DE PROMEDIOS SIMPLES DE RELATIVOS DE PRECIOS: LA MEDIA GEOMÉTRICA. Gabriel Vera Ferrer y Víctor M. Guerrero. Agosto, 1980.

28. LA DEMANDA DE DINERO EN MÉXICO: PRIMERAS ESTIMACIONES. Guillermo Ortiz. Septiembre, 1980.

29. ECONOMÍAS DE ESCALA Y CONCENTRACIÓN BANCARIA: EL CASO DE MÉXICO. Héctor E. González Méndez. Octubre, 1980.

30. LA ESTABILIDAD DE LA DEMANDA DE DINERO EN MÉXICO.

Guillermo Ortiz. Noviembre, 1980.

31. EL TAMAÑO DE LA FAMILIA Y LA DISTRIBUCIÓN DEL INGRESO EN MÉXICO: UN ENSAYO EXPLORATORIO.

Gabriel Vera Ferrer. Diciembre, 1980.

32. PROMEDIOS PARAMETRICOS: SU SELECCIÓN Y EMPLEO EN LA DETERMINACIÓN DE ÍNDICES DE PRECIOS.

Víctor M. Guerrero. Enero, 1981.

33. UNA APLICACIÓN DEL ANÁLISIS DE INTERVENCIÓN A SERIES DE TIEMPO DE LA ECONOMÍA MEXICANA.

Víctor M. Guerrero y Gabriel Vera Ferrer. Marzo, 1981.

34. ALGUNOS ASPECTOS DE LA CONCENTRACIÓN EN EL SISTEMA FINANCIERO MEXICANO.

Héctor E. González Méndez. Marzo, 1981.

35. ANÁLISIS DEL TURISMO RECEPTIVO Y EGRESIVO EN MÉXICO.

Agosto, 1981.

36. COMPORTAMIENTO DE LA FUNCIÓN DE COSTOS DE LA BANCA MÚLTIPLE Y ALTERNATIVAS SOBRE LA EVOLUCIÓN.

Héctor E. González Méndez. Septiembre, 1981.

37. DISTRIBUCIÓN DEL INGRESO EN MÉXICO 1977.

Juan Díez-Canedo y Gabriel Vera. Septiembre, 1981.

38. CUENTAS NACIONALES Y ANÁLISIS MACROECONOMICO.

Jesús Reyes Heroles G. y José J. Sidaoui D. Septiembre, 1981.

39. UNA NOTA SOBRE LA EVOLUCIÓN DE LA ESTRUCTURA DE INGRESOS Y GASTOS BANCARIOS: 1966-1979.

Alain Ize. Octubre, 1981. 
40. LA DOLARIZACIÓN EN MÉXICO: CAUSAS Y CONSECUENCIAS.

Guillermo Ortiz. Octubre, 1981.

41. UN ANÁLISIS DEL MERCADO DE CRÉDITO EN MÉXICO.

Ángel Calderón, Javier Cárdenas y Alain Ize. Octubre, 1981.

42. SUBSTITUCIÓN DE MONEDAS E INDEPENDENCIA MONETARIA: EL CASO DE MÉXICO.

Guillermo Ortiz y Leopoldo Solís. Noviembre, 1981.

43. ESTABILIZACIÓN Y SUBSTITUCIÓN DE ACTIVOS EN UN SISTEMA FINANCIERO CON DOS MONEDAS Y CON EXPECTATIVAS DE DEVALUACIÓN.

Alain Ize. Noviembre, 1981.

44. LA DISTRIBUCIÓN DE LOS INGRESOS POR TRABAJO EN MÉXICO.

Jesús Reyes Heroles G. G. Enero, 1982.

45. DISTRIBUCIÓN REGIONAL DE LA CAPTACIÓN Y EL FINANCIAMIENTO DE LA BANCA PRIVADA Y MIXTA (1950-1980).

Héctor E. González Méndez. Marzo, 1982.

46. COMPORTAMIENTO REGIONAL DE LA CAPTACIÓN Y EL CRÉDITO DE LA BANCA PRIVADA Y MIXTA EN MÉXICO.

Héctor E. González Méndez. Abril, 1982.

47. EVOLUCIÓN Y PERSPECTIVAS DE LAS EXPORTACIONES DE MANUFACTURAS. Javier Salas y José J. Sidaoui D. Mayo, 1982.

48. UN ANÁLISIS DE LA INFLACIÓN EN MÉXICO.

Jesús Marcos Yacamán. Julio, 1982.

49. EL PROCESO INFLACIONARIO EN MÉXICO. TEORÍA Y APLICACIONES DEL ANÁLISIS DE INTERVENCIÓN.

Víctor M. Guerrero. Julio, 1982.

50. ESTRUCTURA ECONÓMICA Y LOS ÍNDICES DE PRECIOS PRODUCTOR.

Marín Maydón Garza y Luis H. Villalpando. Noviembre, 1982.

51. PRECIOS Y PRODUCTO EN EL CORTO PLAZO: ENFOQUES TEÓRICOS ALTERNATIVOS.

Alain Ize. Noviembre, 1982.

52. ESTRUCTURA DE MERCADO, COMPORTAMIENTO Y POLÍTICAS DE LA BANCA PRIVADA Y MIXTA MEXICANA, 1970-1980.

Rubén Yesin Toledo. Noviembre, 1982. 
53. EL COMPORTAMIENTO MACROECONOMICO DE LA ECONOMÍA MEXICANA ENTRE 1961 Y 1981: ESPECIFICACIONES ALTERNATIVAS Y PRUEBAS DE HIPÓTESIS.

Alain Ize y Javier Salas. Agosto, 1983.

54. DESESTACIONALIZACION DE SERIES DE TIEMPO ECONÓMICAS: PARTE I. UNA INTRODUCCIÓN A LA METODOLOGÍA.

Víctor M. Guerrero. Agosto, 1983.

55. DESESTACIONALIZACION DE SERIES DE TIEMPO ECONÓMICAS: PARTE II. AJUSTES PREVIOS A LA DESESTACIONALIZACION.

Víctor M. Guerrero. Agosto, 1983.

56. SOLUCIÓN A UNA CLASE GENERAL DE MODELOS LINEALES EN DIFERENCIAS CON EXPECTATIVAS RACIONALES.

Juan Manuel Pérez Porrúa. Abril, 1984.

57. ANÁLISIS, EVALUACIÓN Y PRONOSTICO DE LA INFLACIÓN EN MÉXICO, MEDIANTE UN MODELO UNIVARIADO DE SERIES DE TIEMPO.

Víctor M. Guerrero. Enero, 1984.

58. LAS TRANSACCIONES FRONTERIZAS EN EL NORTE DE MÉXICO. MARCO CONCEPTUAL Y METODOLOGÍA DE MEDICIÓN.

Alberto Vargas Aguayo. Noviembre, 1984.

59. LAS TRANSACCIONES FRONTERIZAS EN EL PRIMER SEMESTRE DE 1984.

Gabriel Vera Ferrer. Noviembre, 1984.

60. CARACTERÍSTICAS DE UN RÉGIMEN DE PROMOCIÓN DE EXPORTACIONES.

Raúl Miguel Ramos Tercero y Jaime Zabludowsky Kuper. Enero, 1985. 